\title{
Advances in neurology
}

\author{
Colin R Kennedy
}

This is 'the decade of the brain'. Knowledge of mechanisms underlying neurological disease has advanced rapidly using many new investigative tools particularly in cellular biology and molecular genetics. Simultaneously, clinical neurological practice has changed substantially with new imaging techniques and a wider range of therapeutic options particularly in the management of epilepsy.

\section{Molecular genetics in neurological disorders}

LINKAGE ANALYSIS

Inherited neurological diseases, although individually rare, have a collective incidence of over 58 per 100000 population (one per 1700). ${ }^{1}$ The use of restriction fragment length polymorphisms to construct genetic linkage maps for the localisation of disease genes was first suggested 15 years ago. This depends on chromosomal localisation of the disorder rather than isolating the individual gene. Successful application depends on correct diagnosis, heterozygosity for the marker polymorphisms (an 'informative' family), and genetic homogeneity - a single gene locus for the clinical phenotype. The technique is useful for genetic counselling of families, particularly those affected by neuromuscular disorders including Emery-Dreifuss, limb-girdle muscular dystrophies, and spinal muscular atrophy of all types. ${ }^{1}$

\section{GENE IDENTIFICATION}

In some disorders, DNA samples from affected individuals can be tested for alterations of the gene, including point mutations, insertions, and deletions. Unlike linkage analysis, this can be applied to an individual patient without the need for family studies. The proportion of cases in which a mutation can be identified varies widely: for example, $20 \%$ of cases with neurofibromatosis type 1 and $100 \%$ of those with hereditary motor sensory neuropathyCharcot-Marie-Tooth disease-types $1 \mathrm{~A}$ and 1B. ${ }^{1}$

There is a clinical role for this type of testing in at least 14 neuromuscular disorders ${ }^{2}$ and the number is rapidly increasing. Duchenne and Becker muscular dystrophies are the common-

est with identifiable mutations in about $70 \%$. The more severe Duchenne phenotype usually involves deletions that disrupt the translational reading frame of the mRNA triplet codons for the gene product, dystrophin. Although DNA testing alone cannot be used reliably to predict phenotype, characterisation of dystrophin allows alternative strategies for diagnosis when DNA testing is unhelpful or when questions remain in a particular family about the phenotype. DNA testing also plays an invaluable part in carrier detection and prenatal diagnosis..$^{1-3}$ These advances have improved diagnosis and understanding of mechanisms in Duchenne muscular dystrophy and other muscular dystrophies $^{4}$ but have not yet led to useful treatment: gene transfer therapy is a future prospect that awaits development of a viable mode of gene delivery. ${ }^{5}$

A new class of mutation, the trinucleotide repeat, has been identified and found to underlie the fragile $\mathrm{X}$ syndrome, myotonic dystrophy, Huntington's disease, and at least four other degenerative neurological diseases. ${ }^{1-3} 67$ In these diseases, the number of repeats of a base triplet sequence is increased. The expanded sequence is unstable in size and the phenomenon of anticipation occurs: age of onset is lowered and clinical manifestations or phenotype become more severe over successive generations because of progressive increase in size of the repeated segment. Parent of origin effects are marked in the transmission of such 'dynamic' mutations; this helps explain the occurrence of the congenital form of myotonic dystrophy only in children of affected mothers (fig 1); of the juvenile form of Huntington's disease in the children of affected fathers; and of greater anticipation in the children of affected mothers in fragile $X^{3}{ }^{3} 7$

Fragile $\mathrm{X}$ and myotonic dystrophy are multisystem disorders associated with large expansions of repeats and their pathological effect may be due to shutting off gene transcription. Huntington's disease and the other neurodegenerative disorders are caused by smaller expansions of CAG repeats within the protein coding portion of the gene. CAG repeats encode polyglutamine, which has recently been shown to be translated into protein in these disorders and may have its effect by a toxic effect of the polyglutamine ${ }^{6-8}$ perhaps by influ- 


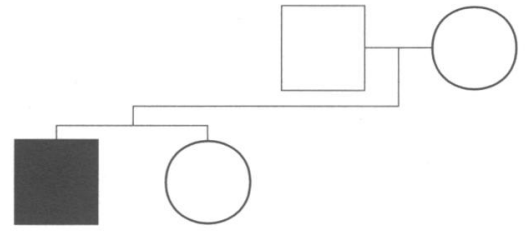

$\mathrm{kb}$

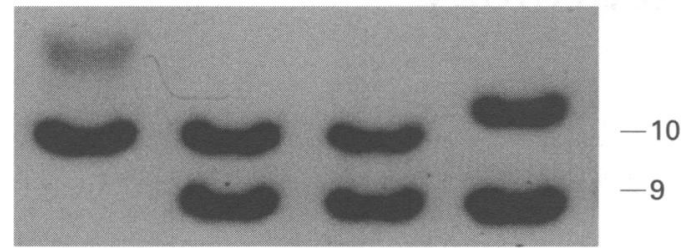

Figure 1 Trinucleotide expansion in myotonic dystrophy. The pedigree shows a family with a son (filled square) presenting with myotonic dystrophy (MD). Using a DNA probe specific for the MD gene, the two alleles of the gene are shown below each member of the family. The normal pattern is of two bands, one of $9 \mathrm{~kb}$ and one of $10 \mathrm{~kb}$, as shown for the sister and father of the proband. The mother and the proband both have an expansion $\left(C T G^{n}\right)$ within the gene. In the mother the expansion is slight. This implies that she has MD but symptoms are likely to be mild and of late onset. The proband has a larger expansion shown by the upper and fainter of his two bands, which is substantially larger than $10 \mathrm{~kb}$. The MD gene has expanded during transmission from mother to son.

encing programmed cell death ${ }^{8}$ (see below). Trinucleotide repeats yet to be identified may also underlie a number of other clinically variable neurological diseases. ${ }^{6}$

Neuronal death and cerebral protection APOPTOSIS: PROGRAMMED CELL DEATH

Loss of neurones is a normal part of central nervous system development in which developmental switches, perhaps related to failure to

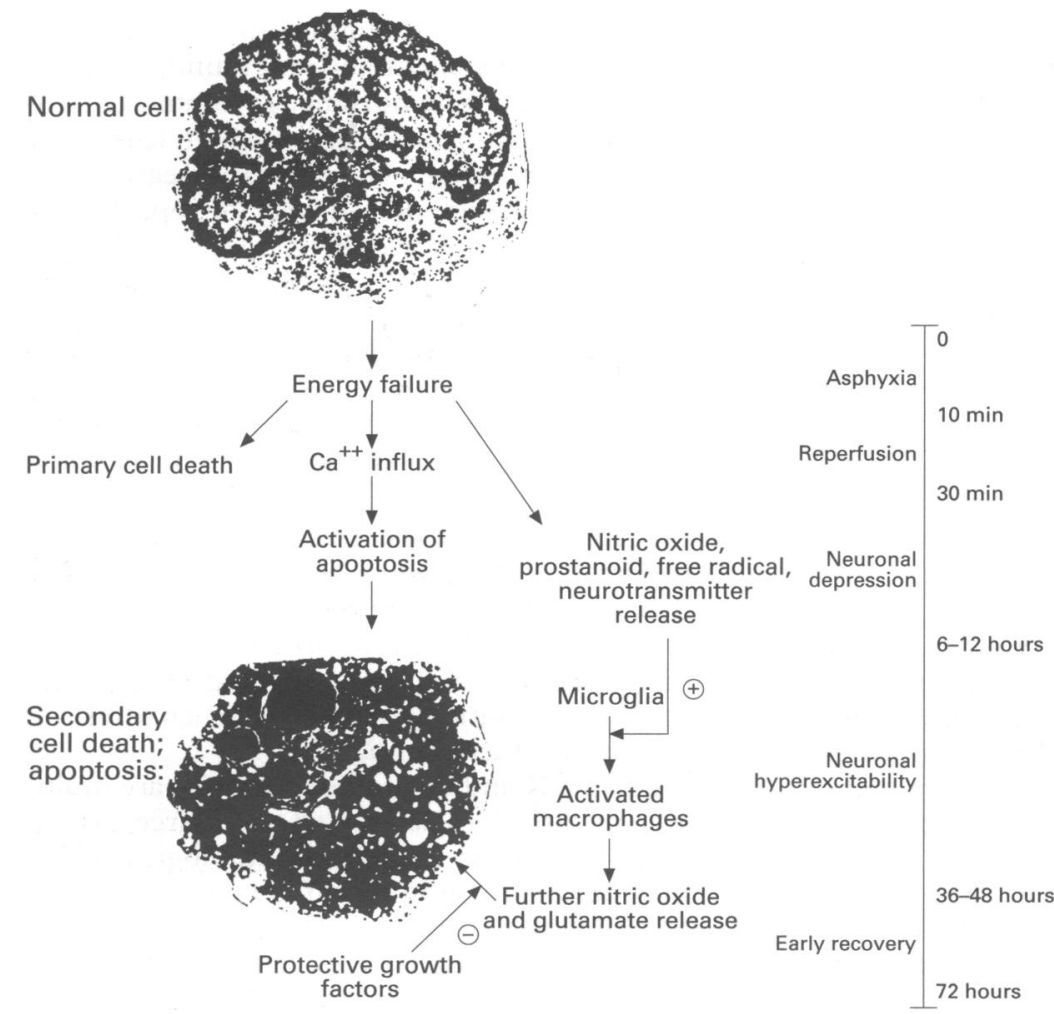

Figure 2 Programmed cell death. Electron micrographs (reproduced by permission of Professor M Raff) of oligodendrocyte precursor cells cultured with (upper micrograph) or without (lower micrograph) insulin, a survival factor. Without insulin, cells die as part of normal development through a process of programmed cell death or apoptosis. Programmed cell death can also be activated by asphyxia or other metabolic insults through a series of steps (see text) summarised in the diagram. establish appropriate trophic connections, trigger cell death. Only a proportion of sensory neurons, for example, receive enough nerve growth factor, released by their target cells, to survive. Similarly, developing glial cells require signals such as platelet derived and insulin-like growth factors from other cells to survive (fig 2). ${ }^{9}$ Neuronal death is also an important part of many neurological diseases whether inflammatory, traumatic, metabolic, or respiratory (hypoxic, ischaemic).$^{10}$ Many experimental studies suggest that asphyxial insults initiate cascades of events for a time after the insult (fig 2) and also that intervention can rescue neurones.

Gluckman and Williams have divided the process into five time periods. ${ }^{10}$ Firstly, the preinsult period with state of maturity, metabolic status, and growth retardation influencing the effect of any subsequent insult. Secondly, there is the insult phase with some 'primary neuronal death'. Energy failure leads to widespread metabolic disruption, sodium and chloride influx, and accumulation of neurotransmitters and intracellular calcium. The latter may lead to inappropriate activation of normally suppressed programmed cell death (apoptosis).

Thirdly, a 10 to 30 minute reperfusion phase is associated with release of cytotoxins including free radicals, prostanoids, and nitric oxide. Cellular energy is restored but neuronal activity remains depressed for some hours perhaps because of inhibitory neuromodulators such as adenosine, opioids, and $\gamma$-aminobutyric acid. Fourthly, six to 12 hours after the insult there is a further period of oedema and metabolic disruption lasting 12 to 48 hours. This is associated with neuronal hyperexcitability and the transformation of microglia into activated macrophages followed by further release of nitric oxide and glutamate. This phagocytic activation may be central to secondary neuronal loss occurring at this time. Finally at 36 to 72 hours neurotrophic factors are induced, such as insulin-like growth factor, fibroblast growth factor, and calcitonin gene related peptide; these appear to be neuroprotective (fig 2).

INTERVENTION STUDIES AND CLINICAL

APPLICATION

Blockade of glutamate receptors, including the much studied $N$-methyl-D-aspartate subtype, reduces damage in some experimental situations. The pattern of cellular events differs between focal and global insults, according to the duration and timing of the asphyxial event ${ }^{11}$ and maturity of the brain. ${ }^{12}$ These variables influence the effect of interventions in experimental studies of asphyxia.

These experimental observations are relevant to clinical situations. Magnetic resonance spectroscopy studies in human infants have shown that acute asphyxia is often associated with a transient reduction in high energy substrates, followed several hours later by a prolonged fall associated with clinical encephalopathy. ${ }^{13}$ These observations support the concept of neuronal damage occurring after a delay of several hours after asphyxia. Raised 
cerebrospinal fluid glutamate concentrations in this clinical situation also support postulated excitotoxicity. ${ }^{14}$

Experimental observations also link excitotoxicity to the prenatal induction of apparently neurodevelopmental disorders such as polymicrogyrias, ${ }^{15}$ to postnatal insults including hypothermic circulatory arrest and tuberculous meningitis, ${ }^{16}$ and to cell death in neurodegenerative diseases (for example Parkinson's and Huntington's diseases). ${ }^{12}$ Careful clinical application of these findings may improve the outcome of a variety of neurological insults in future.

\section{Neuroimaging}

The replacement of pneumoencephalography by computed tomography in the early 1970 s led to a revolution in neurological and neurosurgical practice. Myelography was also improved by the introduction of safer water soluble dye as was angiography by digital subtraction angiography.

A revolution of comparable magnitude has begun with the arrival of magnetic resonance imaging (MRI) and the more recent functional magnetic resonance imaging (fMRI), which have the advantage of avoiding ionising radiation. The basic principles and clinical place of these techniques alongside computed tomography and the radionucleide techniques of positron emission tomography (PET) and single photon emission tomography (SPECT) are the subject of several recent reviews. ${ }^{17-23}$ All methods of obtaining a magnetic resonance signal use radiofrequency pulses to perturb magnetisation in the patient's body water induced by a strong external magnetic field. The slow but robust 'spin echo' techniques are being replaced by faster 'gradient echo' sequences which can be used either to improve localisation or to decrease acquisition time: slices can be acquired in a third of a second and individual scans are repeatable if degraded by patient movement. In functional imaging, echoplanar imaging employs either induction decay over a fraction of a second or a rapid succession of excitation pulses. This explores in detail changes in signals over time likely to result from changing neuronal function.

\section{CLINICAL APPLICATION}

MRI, but not yet fMRI, has become an essential tool in paediatric neurological practice. It has helped to define specific clinical syndromes associated with defects of neuronal migration dating from early fetal life. ${ }^{24-28}$ It has shown abnormalities, rarely visible on computed tomography, underlying common clinical problems such as global developmental delay ${ }^{29}$ and microcephaly ${ }^{30}$ (fig 3 ). MRI has already established its superiority over computed tomography in detecting abnormalities in the spine or near the skull base particularly the posterior fossa. ${ }^{19} 31$ It has also played an important part in managing epilepsy (see below)..$^{21-23}{ }^{28}$ Its role in the diagnosis of neurologically determined birth defects (figs 3-5) will continue to expand as technology is updated leading to more child friendly MRI units and better images. Age spe-

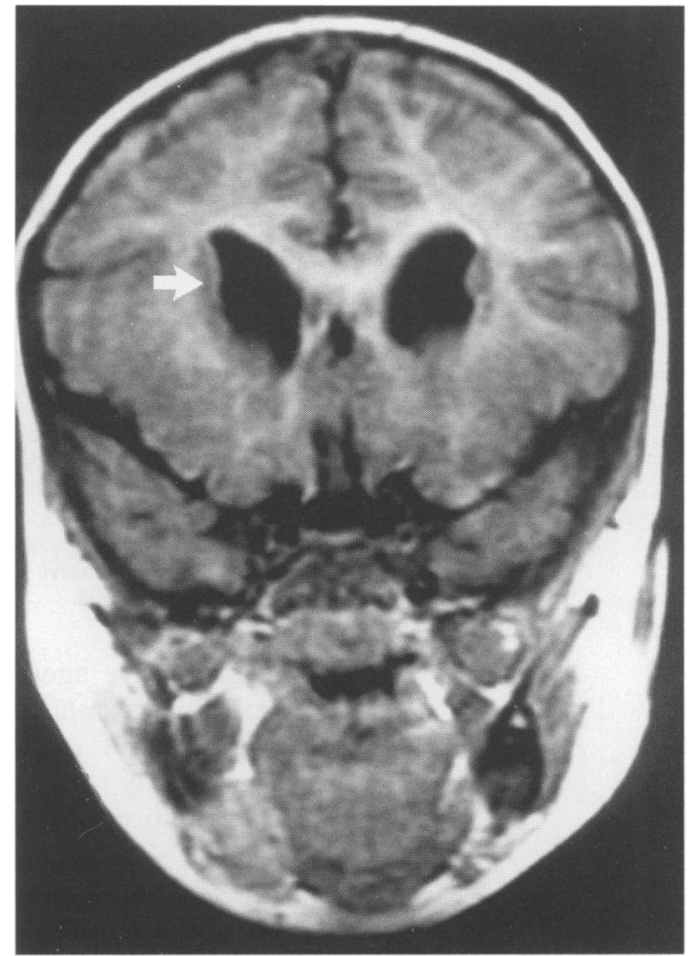

Figure 3 Subependymal heterotopias. Coronal $T_{1}$ weighted MRI of a 2 year old boy with global developmental delay and a mild microcephaly. He had had intraventricular haemorrhage after birth at term.

Heterotopic subependymal grey matter with the signal characteristics of cerebral cortex is seen (white arrow). His neurodevelopmental problems have been attributed to this neuronal migration defect and not to perinatal problems.

cific limits of normality have been defined ${ }^{32}$ and are addressed in the latest neuroradiology reference texts but will need to be refined as the technology to measure volumes and gyral patterns tempts enthusiasts into the zone of incidental findings.

The future role of $\mathrm{fMRI}$ in clinical practice is yet to be defined. Functional imaging is likely to play an important part in the assessment of

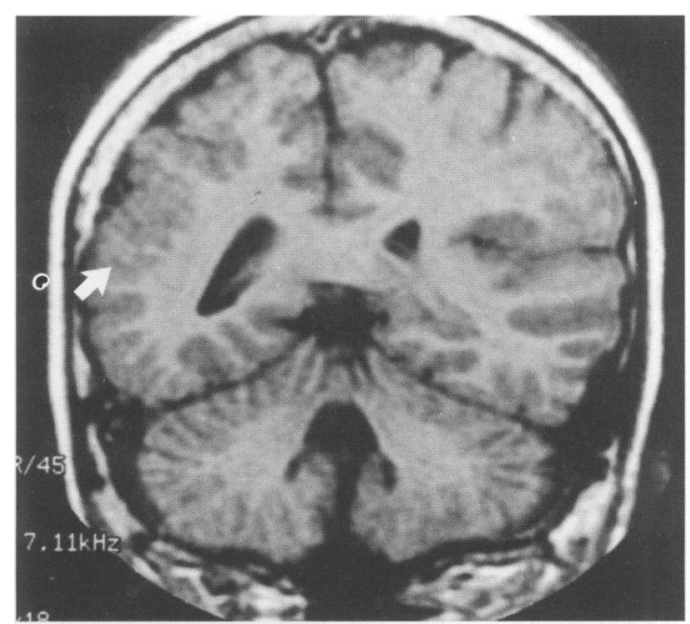

Figure 4 Pachygyria, hemiparesis. Coronal $T_{1}$ weighted MRI of a 12 year old boy with congenital left hemiparesis, normal intelligence, occasional seizures, and a dysphasia progressive over three months associated with continuous epileptiform activity on electroencephalography. Language skills normalised after treatment of this partial status epilepticus. The right hemisphere is atrophic with thickened cortex and poorly formed gyri (white arrow) and sylvian fissure. In the left hemisphere, the posteriorly extended sylvian fissure is seen and the gyral pattern may not be entirely normal. 
Table 1 Drug treatment according to seizure type ${ }^{\star}$

\begin{tabular}{|c|c|c|c|}
\hline & First choice & Second choice & Third choice \\
\hline Partial & Carbamazepine & Vigabatrin & $\begin{array}{l}\text { Sodium } \\
\text { valproate }\end{array}$ \\
\hline $\begin{array}{l}\text { Generalised } \\
\text { tonic-clonic }\end{array}$ & $\begin{array}{l}\text { Sodium } \\
\text { valproate }\end{array}$ & Lamotrigine & Clobazam \\
\hline Absence & Ethosuximide† & $\begin{array}{l}\text { Sodium } \\
\text { valproate }\end{array}$ & Lamotrigine \\
\hline Myoclonic & $\begin{array}{l}\text { Sodium } \\
\text { valproate }\end{array}$ & Lamotrigine & Clonazepam \\
\hline Atonic & Lamotrigine & $\begin{array}{l}\text { Sodium } \\
\text { valproate }\end{array}$ & Clobazam \\
\hline
\end{tabular}

* The relative merits of anticonvulsants in an individual child will be influenced by factors other than seizure type including seizure syndrome (if identifiable), presence of learning disability, behavioural problems, etc.

† Only for absences associated with bilaterally synchronous 3 per second spike and wave on electroencephalography, otherwise known as petit mal.

neuroprotective agents in hypoxia, ischaemia, and cerebrovascular disease but fMRI has yet to displace PET or SPECT either in this field or in assessing movement disorders or presurgical evaluation of intractable epilepsy. ${ }^{2023}$

\section{Epilepsy}

Four areas of significant advance have combined to produce a substantial improvement in the management of suspected epilepsy. Firstly, there have been advances in diagnostic precision. These include distinguishing epilepsy from other paroxysmal events, ${ }^{33}{ }^{34}$ and identifying certain specific syndromes ${ }^{35-37}$ based on seizure type(s), age, associated neurodevelopmental features, family history, and electroencephalography.

Secondly, advances in antiepileptic drug treatment have decreased the number of children in whom seizures are either intractable or controlled at the cost of unacceptable adverse effects (table 1). ${ }^{38-40}$ For example for partial and secondarily generalised epilepsies, ${ }^{38}$ vigabatrin, lamotrigine, gabapentin, and topiramate; for infantile spasms, ${ }^{41}$ vigabatrin; and for Lennox-Gastaut syndrome and generalised epilepsies, ${ }^{38}$ lamotrigine, have all been shown to be effective, sometimes dramatically

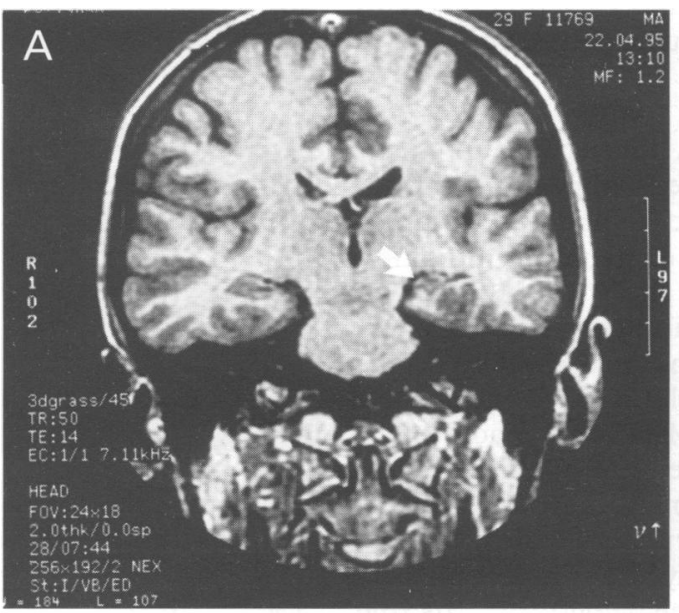

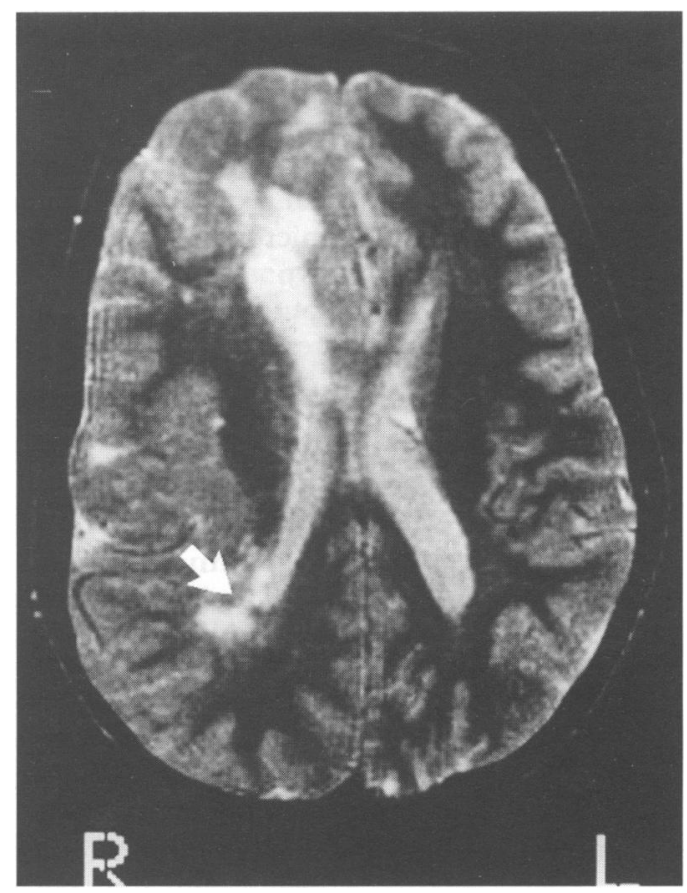

Figure 5 Focal cortical dysplasia and seizures. $T_{2}$ weighted MRI of a 14 year old girl with an 11 year history of poorly controlled partial seizures with secondary generalisation. The right hemisphere is larger than the left. The cortex in the right hemisphere is thickened and does not interdigitate normally with white matter. Right frontal white matter high signal suggests gliosis. There is heterotopic grey matter in the right perisylvian region (white arrow).

in individual patients. This has been accompanied by a resurgence of interest in remediating subclinical and cognitive manifestations of epilepsy. ${ }^{42}$

Thirdly, advances in neuroimaging have helped select those who may benefit from seizure surgery (figs 4-6). ${ }^{21-23}{ }^{28}$ This includes patients with (1) temporal lobe epilepsy with hippocampal sclerosis or alien tissue (fig 6), (2) extratemporal epilepsy with alien tissue in a resectable site, (3) epilepsy with infantile or childhood hemiplegia (fig 4), (4) Rasmussen's encephalitis, (5) drop attacks, and (6) acquired auditory aphasia (Landau-Kleffner syndrome). ${ }^{43}$

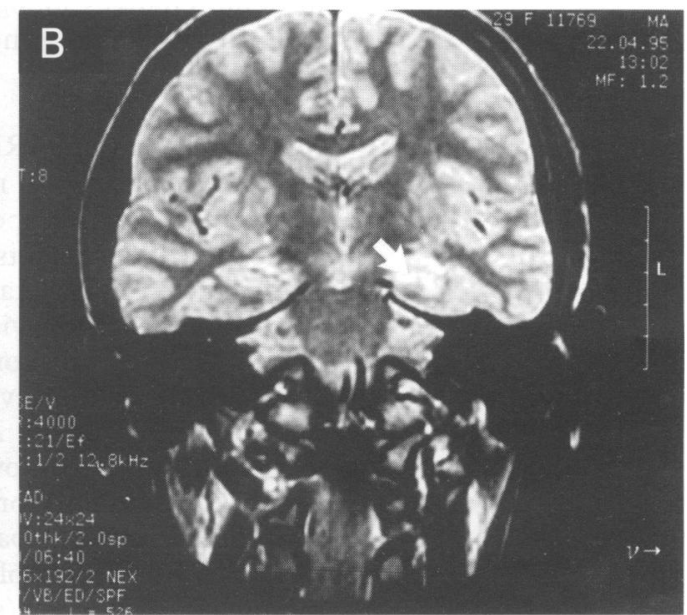

Figure 6 Hippocampal sclerosis and complex partial seizures. $T_{1}$ weighted $(A)$ and proton density (B) MRI of a 29 year old woman with intractable complex partial seizures and associated behavioural problems dating from the age of 18 months. Computed tomography at the age of 14 years was normal. Loss of volume (white arrow in $(A)$ ) and high signal (white arrow in (B)) are interpreted as left hippocampal sclerosis (compare with contralateral structures). These radiological findings are favourable features for surgical treatment. 
Fourthly, the need to disseminate these advances to bring about changes in epilepsy management has led to examination of the 'model of care'. The Epilepsy Task Force has circulated to purchasers $A$ Guide to Good Practice. ${ }^{44}$ There are an increasing number of specialist epilepsy nurses, more written information for families is available, and there is a greater awareness of the central importance of patient and family perceptions of the condition. ${ }^{45}$

Deficiencies in integrating epilepsy care remain. There are similar deficiencies in the care of children with other neurological disorders because of limited resources within individual districts, haphazard patterns of onward referral, and poor coordination between medical and other sectors. Nevertheless, the last five years have seen the consolidation of child development centres and increasing cooperation between the agencies involved in caring for children with neurological disorders. If the promise of molecular genetics and of neuroscience discussed above is fulfilled, further improvements in the model of care will be driven by an increase in the options for effective treatment.

Grateful thanks to Dr John Miller, Professor Martin Raff, and Dr Karen Temple for their help with the figures.

1 MacMillan JC, Harper PS. Clinical genetics in neurologica disease. F Neurol Neurosurg Psychiatry 1994; 57: 7-15.

2 Nadkarni N, Prior TW, Mendell JR. The impact of molecular genetics on the care of patients with muscle disease. Curr Opin Neurol 1994; 7: 435-7.

3 Laing NG. Molecular genetics and genetic counselling for Duchenne/Becker muscular dystrophy. In: Partridge, ed. Molecular and cell biology of muscular dystrophy. London: Chapman and Hall, 1993:37-77.

4 Campbell KP. Three muscular dystrophies: loss of cytoskeleton extracellular matrix linkage. Cell 1995; 80: 675-9.

5 Clemens PR, Caskey CT. Gene therapy prospects for Duchenne muscular dystrophy. Eur Neurol 1994; 34: 181-5.

6 Sutherland GR, Roberts RI. Dynamic mutations on the move. $\mathcal{F}$ Med Genet 1993; 30: 978-81.

7 La Spada AR, Paulson HL, Fischbeck KH. Trinucleotide repeat expansion in neurological disease. Ann Neurol 1994; 36: 814-22.

8 Housman D. Gain of glutamines, gain of function? Nature Genetics 1995; 10: 3-5.

9 Barres BA, Hart IK, Coles SR, et al. Cell death and contro of cell survival in the oligodendrocyte lineage. Cell 1992 70: $31-46$.

10 Gluckman PD, Williams CE. When and why do brain cells die? Dev Med Child Neurol 1992; 32: 1010-4.

11 Gluckman PD, Williams CE. Is the cure worse than the disease? Caveats in the move from laboratory to clinic. Dev Med Child Neurol 1992; 32: 1015-8.

12 Tasker RC. Excitatory amino acid neurotoxicity -a broader horizon for cerebral protection. Arch Dis Child 1992; 67: 1327-8.

13 Azzopardi D, Edwards D. Magnetic resonance spectroscopy in neonates. Curr Opin Neurol 1995; 8: 145-9.

14 Hagberg $H$. Thornberg E, Blennow $M$, et al. Excitatory amino acids in the cerebrospinal fluid of asphyxiated infants: relationship to hypoxic-ischaemic encephalopathy. infants: relationship to hypoxic
15 Marret S, Gressens P, Gadisseux J-F, Evrard P. Prevention by magnesium of excitotoxic neuronal death in the by magnesium of excitotoxic developing brain: an animal study model for clinical inter-

vention studies. Dev Med Child Neurol 1995; 37: 473-84.
Johnston MV. New perspectives on pathogenesis of Johnston MV. New perspectives on pathogenesis of
developmental disorders. Curr Opin Neurol 1995; 8: 131-3. 17 Cherryman GR. Magnetic resonance imaging in paediatCherryman GR. Magnetic resonan
rics. Arch Dis Child 1994; 70: 82-8.

18 Turner R. Magnetic resonance imaging of brain function. Ann Neurol 1994; 35: 637-8.

19 Moseley I. Imaging the adult brain. 7 Neurol Neurosurg Psychiatry 1995; 58: 7-21.

20 Sawle G. Imaging the head: functional imaging. $f$ Neurol Neurosurg Psychiatry 1995; 58: 132-44.

21 Cross JH, Jackson GD, Neville BGR, et al. Early detection of abnormalities in partial epilepsy using magnetic resonance. Arch Dis Child 1993; 69: 104.

22 Jackson GD. New techniques in magnetic resonance and epilepsy. Epilepsies 1994; 35 (suppl 6):52-13.

23 Wieser HG. PET and SPECT in epilepsy. Eur Neurol 1994; 34 (suppl 1): 58-62.

24 Barkovich AJ, Koch TK, Carrol CL. The spectrum of lissencephaly: report of ten patients analysed by magnetic lissencephaly: report of ten patients analysed by

25 Aicardi J. The agyria-pachygyriae complex: a spectrum of cortical malformation. Brain Dev 1991; 13: 1-8.

26 Kuzniecky R, Andermann F, Guerrini R, and CBPS Multicentre Collaborative Study. Congenital bilateral perisylvian centre Collaborative Study. Congenital bilateral perisylvian

syndrome: study of 31 patients. Lancet 1993; 341: 608-12.
Barkovich AJ, Guerrini R, Battagtie G, et al. Band Barkovich AJ, Guerrini R, Battagtie G, et al. Band
heterotopia: correlation of outcome with magnetic resonance imaging parameters. Ann Neurol 1994; 36: 609-17.

28 Raymond AA, Fish DR, Sisodiya SM, Alsanjari N, Stevens JM, Sharvon DS. Abnormalities of gyration, heterotopies, tuberous sclerosis, focal cortical dysplasia, microdysgenesis, dysembryoplastic neuro-epithelial tumour and dysgenesis of the archi cortex in epilepsy. Brain 1995; 118: 629-60.

29 Harbord MG, Finn JP, Hall-Craggs MA, Robb SA, Kendall BE, Boyd SG. Myelination patterns on magnetic resonance of children with developmental delay. Dev Med Child Neurol 1990; 40: 1869-75.

30 Sugimoto T, Yasuhara A, Nishida A, Murakami K, Woo M, Kobayashi Y. MRI of the head in the evaluation of microcephaly. Neuropediatrics 1993; 24: 4-7.

31 Elias-Jones AC, Jaspar T, Mellor DH, Worthington BS Magnetic resonance imaging in neurological disorders. Magnetic resonance imaging in

32 Grodd W. Normal and abnormal patterns of myelin development of the fetal and infantile human brain using magnetic resonance imaging. Curr Opin Neurol Neurosurg 1993; 6: 393-7.

33 Stephenson JBP. Fits and faints. Clinics in developmental medicine No 109. MacKeith Press (Oxford: Blackwells), 1990.

34 Stores G. Confusions concerning sleep disorders and the epilepsies in children and adolescents. Br F Psychiatry 1991, 158: $1-7$.

35 Aicardi J. Syndromic classification in the management of childhood epilepsy. $f$ Child Neurol 1994; 9 (suppl 2): 14-8.

36 Panayiotopoulos CP. Benign childhood partial epilepsies: benign childhood seizure susceptibility syndromes. $\mathcal{f}$ Neurol Neurosurg Psychiatry 1993; 56: 2-5.

37 Deurol Neurosurg Psychiatry 1993; 56: 2-5. 102-6.

38 Wallace SJ. Drug management of epilepsy. Dev Med Child Neurol 1992; 32: 1018-21.

39 Dodson WE, Bourgeois BF. Pharmacology and therapeutic aspects of antiepileptic drugs in pediatrics. $\mathcal{f}$ Child Neurol 1994; 9 (suppl 2):1-7.

40 Livingston JH. Management of intractable epilepsy. Arch Dis Child 1991; 66: 1454-6.

41 Appleton RE. Infantile spasms. Arch Dis Child 1993; 69: 614-8.

42 Deonna TW. Acquired epileptiform aphasia in children (Landau-Kleffiner syndrome). $\mathcal{F}$ Clin Neurophysiol 1991; 8: 288-98.

43 Sawhnay IM, Robertson J, Polkey CE, Binnie CD, Elwes RD. Multiple subpial transaction: a review of 21 cases. $\mathcal{F}$ Neurol Neurosurg Psychiatry 1995; 58: 344-9.

44 Epilepsy Task Force. Purchasing and providing epilepsy out-patient services: a guide to good practice. London: Shire out-patient services: a guide to

45 Devinsky $O$. Outcome research in neurology: incorporating health-related quality of life. Ann Neurol 1995; 37: 141-2. 